\title{
Jaccoud's arthropathy
}

\section{A case report and necropsy study}

F. L. GIRGIS, * A. W. POPPLE, AND F. E. BRUCKNER

From the Departments of Rheumatology and Histopathology, St. George's Hospital, London

SUMMARY We present a case of Jaccoud's arthropathy in a 59-year-old woman. She developed painless correctable ulnar deviation at the metacarpophalangeal joints of both hands following 4 attacks of rheumatic fever. Radiology did not show the hook lesions previously described, but we do not consider this sign essential for the diagnosis. There was no clinical evidence of rheumatoid arthritis. We were able to examine 3 complete joints from the left little finger at necropsy. Pathological examination of this kind has been possible only once before. The histological findings were fibrous thickening of the joint capsule, secondary degenerative changes, presumably due to longstanding joint deformity, and no evidence of significant synovial pathology.

The relationship between chronic valvular heart disease and chronic deforming arthritis is of great interest. Among the least common is the chronic post-rheumatic fever arthritis of Jaccoud (1869).

It is important to make the correct diagnosis to reassure the patient of the benign nature of the arthritis, and to avoid subjecting him to unnecessary treatment with anti-rheumatic drugs. These interfere with control of the concomitant anti-coagulant therapy in patients with atrial fibrillation from severe rheumatic heart disease, as well as having toxic effects in their own right.

Only 1 patient with classical clinical features of this condition has hitherto come to necropsy. We, therefore, present the second case of Jaccoud's arthropathy, who came to necropsy.

\section{Case report}

The proposita, a housewife, born November 10, 1910 presented at the age of 60 with severe exertional dyspnoea, orthopnoea, and ankle swelling. She gave a history of recurrent attacks of rheumatic fever at the ages of $11,14,17$, and 37 . At the age of 44 she became breathless on exertion. Her mother had crippling arthritis.

On examination she had a malar flush and was cyanosed. There was ankle oedema. In the cardiovascular system the pulse showed atrial fibrillation and the jugular venous pressure was elevated. The

Accepted for publication February 17, 1978

* Present address: Department of Rheumatology, St. Mary's Hospital, London. heart was enlarged and there was evidence of mitral stenosis and incompetence, namely a loud pansystolic murmur, a moderately loud opening snap, and a long, loud mitral diastolic murmur.

Chest $x$-ray showed considerable cardiac enlargement, an enlarged left atrium, pulmonary congestion, and marked right ventricular prominence. In the electrocardiogram there was evidence of atrial fibrillation and the effects of digitalis therapy. Right and left heart catheterisation confirmed (1) mitral stenosis and incompetence and suggested (2) recent pulmonary emboli and (3) minimal aortic valve disease.

Two years later she was referred to the Rheumatology Department at St. George's Hospital because of stiffness and ulnar deviation of her fingers.

The following additional history was elicited. She had noticed ulnar deviation of the fingers following the third attack of rheumatic fever at the age of 17 . At the age of 50 she had developed intermittent pain of the wrists, hands and feet with swelling of the metacarpophalangeal (MCP) joints.

On examination, there were no subcutaneous nodules and no evidence of active joint inflammation. There was reversible ulnar deviation of the fingers in the hands which was more pronounced in the right than the left, and capsular thickening of the MCP joints and subluxation of the right 5th MCP joint (Fig. 1). There was bilateral hallux valgus with metatarso-phalangeal subluxation in the feet. Other joints were normal.

$X$-rays of the hands (Fig. 2) showed ulnar deviation at the MCP joints. There was no peri-articular 


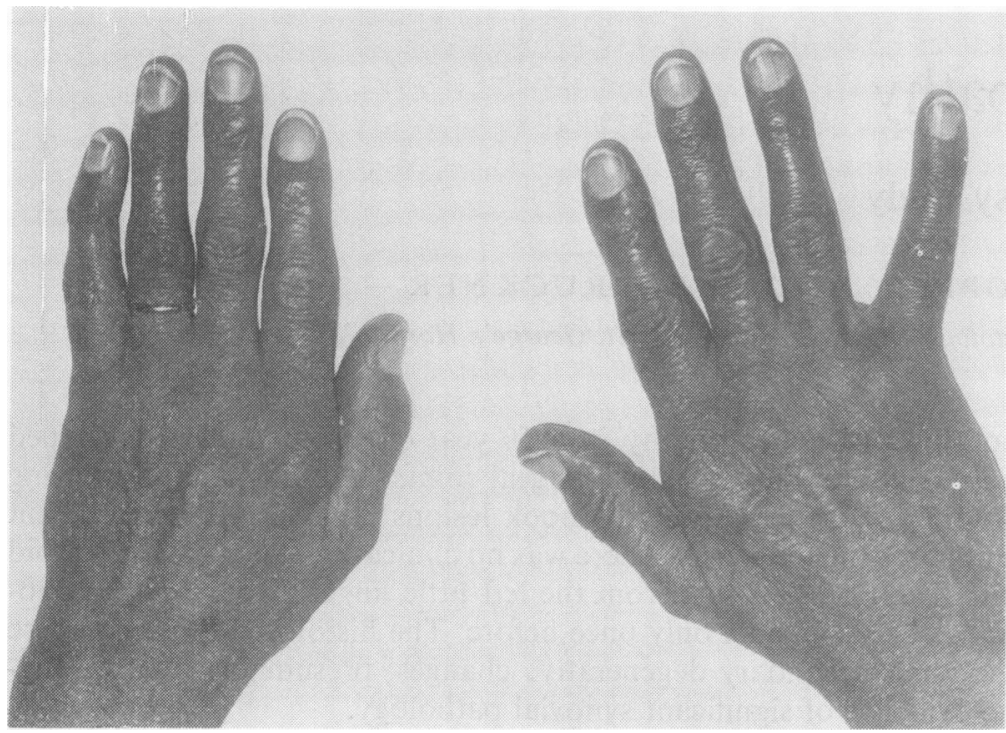

Fig. 1 Hands to show ulnar

deviation which was reversible and capsular thickening of $\mathrm{MCP}$ joints.

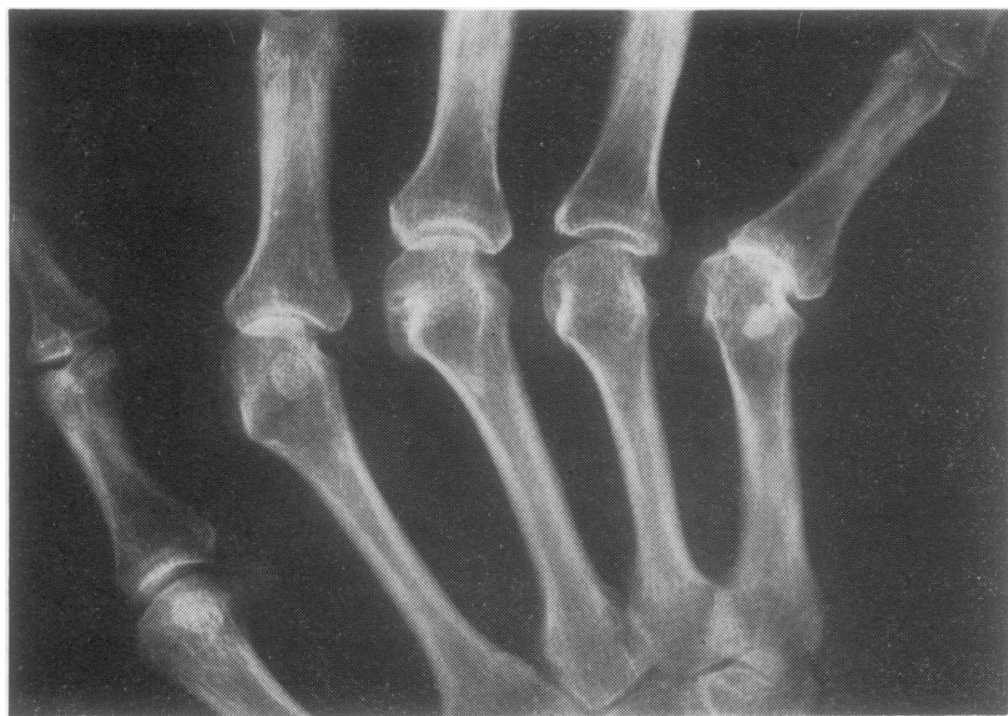

Fig. $2 X$-ray of right hand showing ulnar deviation with subluxation of MCP joints especially on the right.

There are loss of joint space, sclerosis, and cysts most prominent at the MCP joint of the little finger. There are no hook lesions and there are no rheumatoid erosions.

osteoporosis or erosion. Osteophytes and cysts suggested secondary degenerative changes, most marked in the MCP joints of the right hand. $X$-rays of feet showed bilateral hallux valgus and osteoarthritic changes only. Erythrocyte sedimentation rate (Westergren) was $15 \mathrm{~mm} /$ hour and tests for rheumatoid factor and anti-nuclear antibodies were negative.

A diagnosis of Jaccoud's arthropathy was made. At the age of 65 she was admitted because of deteriorating cardiac function and died in hospital 3 months later.

\section{Pathology}

At necropsy, in addition to the external appearances of the hands and feet noted clinically, typical rheumatic heart valve disease was seen. The heart weighed $550 \mathrm{~g}$, and there were dilatation of both atria and hypertrophy of both ventricles. Cusp fusion an chordial contraction was seen in the mitral value and cusp fusion and distortion was present in the aortic valve. The tricuspid valve ring was dilated? but a small degree of cusp fusion was also found. 7 The fifth phalanx of the left hand was sectione 
and microscopically studied. The MCP and (to a lesser extent) the interphalangeal joints showed degenerative changes; namely fibrillation of cartilage, focal total loss of cartilage with underlying eburnation of bone, peripheral osteophytes, and subchondral microcysts (Fig. 3). The joint capsule was greatly thickened. Most of the thickening consisted of rather dense acellular fibrous tissue (Fig. 4) Minor lateral synovial encroachment into the joint space and some fibrin formation were noted. There was no histological evidence of active synovitis and in particular there was no evidence of rheumatoid arthritis.

\section{Discussion}

Bywaters (1950) suggested three types of association

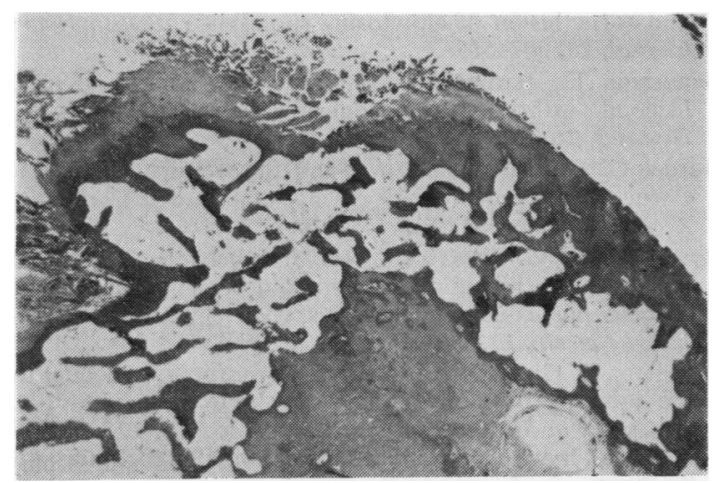

Fig. 3 MCP joint showing fibrillation of cartilage, eburnation of bone, and early osteophyte and microcyst formation. (Haematoxylin and eosin, $\times 20$.

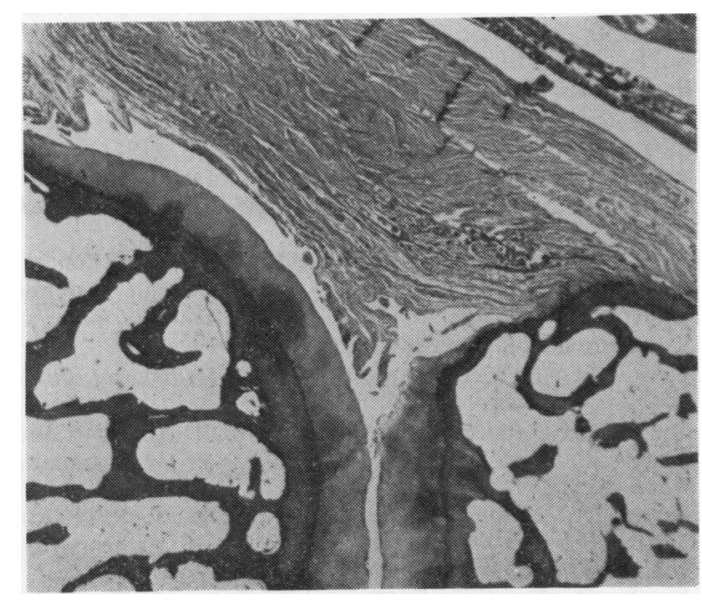

Fig. 4 PIP joint showing capsular thickening due to dense fibrous tissue. (Haematoxylin and eosin, $\times 20$ ). between chronic valvular heart disease and chronic deforming arthritis:-

(1) Rheumatoid arthritis developing in a patient suffering from rheumatic heart disease.

(2) Rheumatoid granulomata involving the heart valves.

(3) Chronic post-rheumatic fever arthritis (Jaccoud's type).

Later this list was enlarged:-

(4) Ankylosing spondylitis associated with aortic ring dilation and aortic incompetence. (Ansell et al., 1958; Graham and Smythe, 1958.)

(5) Reiter's disease and cardiac valvular lesions. (Csonka et al., 1961).

(6) Osteoarthritis in a patient with rheumatic heart disease (Beausang et al., 1967).

(7) Systemic lupus erythematosus (SLE). Bywaters (1975) suggests that a chronic deforming arthritis occurs in about $4 \%$ of cases of SLE. The joints most frequently affected are the finger joints (symmetrically), the wrists, and the knees. (Bywaters and Scott, 1965; Hahn et al., 1970; Dubois et al., 1972.)

Jaccoud, in 1869, described the chronic arthritis appearing after recurrent severe attacks of rheumatic fever, which he named chronic fibrous rheumatism. His patient, who was 29 years of age, developed deformity of hands and feet following the third attack of rheumatic fever. They were in the form of ulnar deviation of the MCP and hyper-extension of the proximal interphalangeal (PIP) joints of the index, middle and ring fingers. There was no bony destruction. He also had aortic stenosis and incompetence.

In 1950, Bywaters described 5 cases of Jaccoud's arthropathy and suggested these cardinal features for the diagnosis of the condition. (1) A history of recurrent severe and prolonged attacks of rheumatic fever. (2) Delayed recovery associated with stiffness in the MCP joints, which may result in ulnar deviation later. (3) The ulnar deviation is correctable by voluntary effort in the early stages. There may also be hyperextension at the PIP joints, though these are not themselves swollen. (4) Tendon crepitus may be elicited. (5) Disease is inactive with a normal ESR and often few or no joint symptoms. There is little impairment of function. (6) Radiologically the earliest bone change is erosion of the metacarpal heads on the most palmar and radial part of their circumference in the antero-posterior projection, producing later hook-like erosions. (7) The Rose-Waaler test for rheumatoid factor is negative (8) There is capsular fibrosis and no evidence of synovitis or synovial fibrosis.

Since 1950, cases have been reported by Bywaters (1950; 1975), Short et al. (1957), Engleman (1960), Zvaifler (1962; 1966), Twigg and Smith (1963), 
Dimitriu et al. (1964), Ruderman and Abruzzo (1966), Beausang et al. (1967), Burda et al. (1967), Cabanel et al. (1969), Katona et al. (1969), Vachtenheim and Bosmansky (1969), and Grahame et al. (1970).

Despite this extensive literature some authors still doubt the existence of Jaccoud's arthropathy as a separate clinical entity, and suggest that these are patients with rheumatic heart disease and mild rheumatoid arthritis that has 'burnt out'. (Hollander and McCarthy, 1972, American Rheumatism Association, 1964, Burda et al., 1967).

The underlying causes of the characteristic hand deformities are not well understood. Jaccoud (1869) and Bywaters (1950) reported that the chief changes are found in the joint capsules which become distended. The tendons slip to the ulnar side of the MCP joints, and, with subsequent tendon shortening, pull the phalanges obliquely in the ulnar direction. The little finger is most severely involved because of the absence of a barrier to the ulnar deflection. Keil (1938) and Bywaters (1950) noted that rheumatic fever nodules may affect the flexor tendons and give rise to tendon shortening. Bywaters (1950) suggested that fibrosis of peri-articular structures plays a prominent part, and our findings support this.

Bywaters (1950) noted the occurrence of subcutaneous nodules on the elbow of one of his patients (O.L.) though later these nodules disappeared. Similar transient subcutaneous nodules were noted in Jaccoud's arthropathy by Ruderman and Abruzzo (1966). Histological examination of a nodule revealed a central area of fibrinoid degeneration with necrosis, surrounded by a cellular zone of large mononuclear cells and small round cells located more peripherally. These nodules may resemble histologically the classical rheumatoid nodule or present an intermediate appearance between those of rheumatoid arthritis and rheumatic fever.

The hook lesion of Jaccoud's arthropathy results from long continued ulnar deviation. Anatomically it is seen as an adaptive change to altered stress. It occurs also in SLE and rheumatoid arthritis and may occur in old age and Parkinsonism (Bywaters, 1975). It was not seen in our patient and cannot be regarded as a cardinal feature.

Bywaters (1950) had a necropsy examination of the joints of one of his patients with Jaccoud's arthropathy and histology was also available from joint biopsies in a further two cases. Sections showed synovial infiltration with lymphocytes, plasma cells, and pigment containing macrophages. In only one specimen was capsular fibrosis mentioned.

In our case the microscopical appearances of cartilage and bone in the articular region were of a nonspecific degenerative nature, possibly as a result of chronic malalignment of the joint. The appearances of peri-articular thickening and fibrosis are more striking than those previously described. However, $\frac{\mathrm{C}}{\mathrm{c}}$ in view of the extensive degenerative changes seen in the joint it is impossible to say whether the capsular fibrosis is due to the chronic trauma of malaligned $\overrightarrow{0}$ joints or a primary result of repeated attacks of $\frac{}{0}$ rheumatic fever. The minimal synovial changes $\frac{\bar{m}}{\sqrt{2}}$

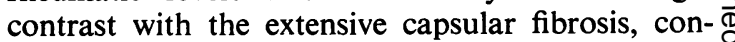
firming that 'burnt out' rheumatoid arthritis played no part in the pathogenesis of the proposita's arthropathy.

\section{References}

American Rheumatism Associaticn (1964). Primer on the rheumatic diseases, Part I. Journal of the American Medical ${ }^{\omega}$ Association, 190, 127-140.

Ansell, B. M., Bywaters, E. G. L., and Doniach, I. (1958). The aortic lesion of ankylosing spondylitis. British Heart Journal, 20, 507-515.

Beausang, E., Barnett, E. V., and Goldstein, S. (1967). 을 Jaccoud's arthritis-a case report. Annals of the Rheumatic Diseases, 26, 239-245.

Burda, C. D., Sanders, C. V., and Shreveport, L. (1967).尺 Chronic post-rheumatic fever (Jaccoud's) arthritis. 3 Archives of Internal Medicine, 120, 712-716.

Bywaters, E. G. L. (1950). Relation between heart and joint disease including 'rheumatoid heart disease' and $\vec{\theta}$ chronic post-rheumatic arthritis (type Jaccoud). Brites Heart Journal, 12, 101-131.

Bywaters, E. G. L. (1975). Jaccoud's syndrome-a sequelậo the joint involvement of systemic lupus erythematosus. In Clinics in Rheumatic Diseases, vol. 1,1, p. 125, ed. by E. G. L. Bywaters. Saunders: London, Philadelphia andō Toronto.

Bywaters, E. G. L., and Scott, J. T. (1965). Systemic disease of connective tissue. In Progress in Clinical Rheumatology, p. 114, ed. by Allan St. J. Dixon. Churchill: London.

Cabanel, G., Phelip, X., Gras, J. P., and Verdier, J. M. (1969). The problem of chronic arthropathies following? acute articular rheumatism. Revue Lyonnaise de Medecine? 18, 61-71.

Csonka, G. W., Litchfield, J. W. Oates, J. K., and Willcox R. R. (1961). Cardiac lesions in Reiter's disease. British Medical Journal, 1, 243-247.

Dimitriu, C. G., Nestor, R., and Schläfer, B. (1964). Con tributions to the study of the dislocating form of Bouillaud Sokolski's rheumatism. Rumanian Medical Review, 18, 18-22.

Dubois, E. L., Friou, G. J., and Chandor, S. (1972). Rheuma toid nodules and rheumatoid granulomas in systemict lupus erythematosus. Journal of the American Medica? Association, 220, 515-518.

Engleman, E. P. (1960). Questionnaire. Archives of Inter American Rheumatology, 3, 616.

Graham, D. C., and Smythe, H. A. (1958). The carditis anc aortitis of ankylosing spondylitis. Bulletin of the Rheumatici

Diseases, 9, 171-174.
Grahame, R., Mitchell, A. B. S., and Scott, J. T. (1970) Chronic post-rheumatic fever (Jaccoud's) arthropathy Annals of the Rheumatic Diseases, 29, 622-625.

Hahn, B. H., Yardley, J. H., and Stevens, M. B. (1970)? 'Rheumatoid' nodules in systemic lupus erythematosus. Annals of Internal Medicine, 72, 49-58. 
Hollander, J. L., and McCarthy, D. J. (1972). Arthritis and Allied Conditions: A Textbook of Rheumatology, 8th ed. Lea and Febiger: Philadelphia.

Jaccoud, F. S. (1869). Leçons de Clinique Mèdicale faites a l'Hôpital de la charité, 2nd ed. Delahaye: Paris.

Katona, G., Pereira, C. B., and Robles, G. J. (1969). Postrheumatic fever arthropathy or Jaccoud's syndrome. In Pan-American Rheumatology, p. 305. Excerpta Medica Foundation: Amsterdam.

Keil, H. (1938). The rheumatic subcutaneous nodules and simulating lesions. Medicine (Baltimore), 17, 261-380.

Ruderman, J. E., and Abruzzo, J. L. (1966). Arthritis rounds (4). Chronic post-rheumatic fever arthritis (Jaccoud's). Report of a case with subcutaneous nodules. Arthritis and Rheumatism, 9, 640-647.
Short, C. L., Bauer, W., and Reynolds, W. E. (1957). Rheumatoid Arthritis: $A$ Definition of the Disease and a Clinical Description Based on a Numerical Study of 293 Patients and Controls, p. 22. Harvard University Press: Cambridge, Mass.

Twigg, H. L., and Smith, B. F. (1963). Jaccoud's arthritis. Radiology, 80, 417-421.

Vachtenheim, I., and Bosmansky, K. (1969). Die Jaccoudsche Arthropathie. Zeitschrift für RheumaForschung, 28, 191-200.

Zvaifler, N. J. (1962). Chronic post-rheumatic fever (Jaccoud's) arthritis. New England Journal of Medicine, 267, 10-14.

Zvaifler, N. J. (1966). Arthritis rounds (4). Discussion. Arthritis and Rheumatism, 9, 646-647. 